\title{
The safety and efficacy of Glubran 2 as biliostatic agent in liver resection
}

\author{
Renato Patrone ${ }^{1}$, Vincenza Granata ${ }^{2,3^{*}}$, Andrea Belli ${ }^{4}$, Raffaele Palaia ${ }^{4}$, Vittorio Albino ${ }^{4}$, Mauro Piccirillo ${ }^{4}$, \\ Roberta Fusco ${ }^{2}$, Fabiana Tatangelo ${ }^{5}$, Guglielmo Nasti ${ }^{6}$, Antonio Avallone ${ }^{6}$ and Francesco Izzo ${ }^{4}$
}

\begin{abstract}
Background: Biloma, an encapsulated collection of bile outside the biliary tree, supported by a predominantly iatrogenic biliary fistula, and bile likeage are two of the most important surgical complications after liver resection. We, hypothesized to conduct a project aimed to prevent, or reduce, the formation of biloma or biliary fistula applying on the hepatic resection area the cyanoacrylate glue (Glubran2).
\end{abstract}

Methods: We searched in our surgical database all patients underwent liver resection for mCRC from January 2013 to December 2018 and we found a total of 510 patients. 205 patients for Group A (study population: included patients in which we have used Glubran2 during surgical procedure) and 113 patients for Group B (control group), were enrolled.

Results: In both Groups no patients died during hospitalization and the 30-day mortality was $0 \%$. During follow-up in Group A, a biliary fistula was found in 2 patients (1 \%) versus 3 patients in the Group B (2,6\%). In patients enrolled in Group A no adverse event were reported relate to the use of Glubran2.

Conclusions: It is possible to affirm that the use of Glubran2 as biliostatic agent after liver resection is useful to prevent bile leakage complication and biloma formation and its use demonstrated to be safe and feasible during liver surgery.

Keywords: Liver metastases, Bile duct injury, Hepatic resection, Chemotherapy, Efficacy

\section{Background}

The only curative option for patients with colorectal liver metastases (mCRC) enabling 5-year overall survival rates of $50 \%$, is hepatic resection [1,2]. Effective oxaliplatin- and irinotecan-based chemotherapy protocols associated with targeted agents have significantly improved response rates, conversion to resectability and long-term survival in mCRC patients [1]. However, nevertheless the benefit of neoadjuvant chemotherapy, there are a number of chemotherapy-effects that have an influence

\footnotetext{
* Correspondence: v.granata@istitutotumori.na.it

${ }^{2}$ Department of Support to Cancer Pathways Diagnostics Area, Radiology Unit, "Istituto Nazionale Tumori IRCCS Fondazione Pascale - IRCCS di Napoli", Naples, Italy

${ }^{3}$ Radiology Division, "Istituto Nazionale Tumori IRCCS Fondazione Pascale IRCCS di Napoli", Naples, Italy

Full list of author information is available at the end of the article
}

on surgical morbidity. The chemotherapy-related complications, steatosis, chemotherapy-associated steatohepatitis (CASH) and sinusoidal obstruction syndrome (SOS), might impair the hepatic parenchyma, thus reducing the functionality and influencing the outcome following resection [1-3]. One of the most serious complication reported in Literature, related to liver surgery, are the biliary system iatrogenic injury with an important rate from 3.6 to $17 \%$ depending on several clinical risk factor [3-7]. Due to an increase of postoperative mortality rates related to biliary complications the use of topical hemostatic agents have been recommended [4, 5, 8-10]. Nonetheless, in Literature, only few study focused attention on the use of these agents to prevent complication related to liver resection [11-15]. In this study, the topical hemostatic agent used was a new synthetic

(c) The Author(s). 2021 Open Access This article is licensed under a Creative Commons Attribution 4.0 International License, which permits use, sharing, adaptation, distribution and reproduction in any medium or format, as long as you give appropriate credit to the original author(s) and the source, provide a link to the Creative Commons licence, and indicate if changes were made. The images or other third party material in this article are included in the article's Creative Commons licence, unless indicated otherwise in a credit line to the material. If material is not included in the article's Creative Commons licence and your intended use is not permitted by statutory regulation or exceeds the permitted use, you will need to obtain permission directly from the copyright holder. To view a copy of this licence, visit http://creativecommons.org/licenses/by/4.0/ The Creative Commons Public Domain Dedication waiver (http://creativecommons.org/publicdomain/zero/1.0/) applies to the data made available in this article, unless otherwise stated in a credit line to the data. 
cyanoacrylate glue called Glubran2, tested in various surgery with promising results [16-18]. Our primary endpoint is to test the safety and feasibility of Glubran2 during surgical liver resection in patients with mCRC previously treated with chemotherapy; as secondary endpoint we selected the utility of this agent to prevent biloma or biliary fistula to assess its biliostatic effect.

\section{Methods}

\section{Study population}

We searched, in the surgical database of the National Cancer Institute of Naples, all patients who underwent liver resection for mCRC from January 2013 to December 2018 and we found a total of 510 patients. From this total number we divided patients in two groups: Group A (study population) included patients in which we have used Glubran2 after liver resection, and Group B (control group).

This retrospective study was approved by the Ethical Committee of the National Cancer Institute "G. Pascale Foundation - IRCCS" of Naples and the requirement for patient informed consent was waived.

The inclusion criteria for the study population and control group were: (a) patients who had pathologically proven mCRC; (b) patients who had undergone imaging studies within 1 month to surgical procedure; and (c) patients who had been subjected to the same neo-adjuvant treatments. The exclusion criteria were: (a) discrepancy between the pre-surgical diagnosis and the pathologically confirmed diagnosis, (b) no available follow-up imaging studies.

During the study period, 205 patients for Group A and 113 patients for Group B, were enrolled in the study that fulfilled the inclusion criteria.

Characteristics of patients from both groups are summarized in Table 1.

\section{Chemotherapy protocol}

Both groups of patients received neoadjuvant mFOLFOX6 (5-fluorouracil, leucovorin, oxaliplatin) plus bevacizumab. mFOLFOX6 was administered IV every 14 days with oxaliplatin $85 \mathrm{mg} / \mathrm{m}-2$ by infusion on day1, followed by leucovorin $200 \mathrm{mg} / \mathrm{m}-2$ infusion on day 1 , followed by 5 -fluorouracil $400 \mathrm{mg} / \mathrm{m}-2$ bolus on day 1 , and 5-fluorouracil $2400 \mathrm{mg} / \mathrm{m}^{-2} 46-\mathrm{h}$ continuous infusion. The antiangiogenic drug Bevacizumab was administered every 14 day-sat $5 \mathrm{mg} / \mathrm{kg}$ by IV infusion over $90 \mathrm{~min}$ at the first cycle, and then, if adequately tolerated, over $60 \mathrm{~min}$. The treatment of mFOLFOX6 plus bevacizumab was administered for a total of 6 cycles.

\section{Surgical procedure}

All resections were initiated with curative intent. Surgical exploration and intra-operative ultrasound were performed in all cases to detect occult tumors and to plan appropriate resections. Resections of all metastatic sites

Table 1 Datation regarding the MR imaging pps

\begin{tabular}{|c|c|c|c|}
\hline & mCRC patients (no. $=205$ ) & Control patients (no. $=113$ ) & $P$ value \\
\hline \multicolumn{4}{|l|}{ Demographics } \\
\hline \multirow[t]{2}{*}{ Gender } & Men 89 (43.4\%) & Men 64 (56.6\%) & 0.89 \\
\hline & Women 116 (56.6\%) & Women 49 (43.4\%) & 0.89 \\
\hline \multirow[t]{2}{*}{ Age } & Mean, 56 years & Mean, 48 years & 0.74 \\
\hline & Range, $33-80$ years & Range, $35-78$ years & \\
\hline \multicolumn{4}{|l|}{ Primary cancer site } \\
\hline Colon & $94(45.9 \%)$ & $52(46 \%)$ & 0.92 \\
\hline Rectum & $111(54.1 \%)$ & $61(54 \%)$ & 0.92 \\
\hline History of chemotherapy & $205(100 \%)$ & $113(100 \%)$ & 0.99 \\
\hline Chemotherapy protocol & $\begin{array}{l}\text { mFOLFOX6 (5-fluorouracil, leucovorin, } \\
\text { oxaliplatin) plus bevacizumab } 205 \text { (100\%) }\end{array}$ & $\begin{array}{l}\text { mFOLFOX6 (5-fluorouracil, leucovorin, } \\
\text { oxaliplatin) plus bevacizumab } 113 \text { (100\%) }\end{array}$ & \\
\hline \multicolumn{4}{|l|}{ Liver metastases } \\
\hline \multirow[t]{3}{*}{ Number } & 1075 & 452 & \\
\hline & mean 4 per patient & mean 5 per patient & \\
\hline & range 1-7 per patient & range 2-6 per patient & \\
\hline \multirow[t]{2}{*}{ Largest diameter } & mean 32 mm & mean 28 mm & \\
\hline & range $8-64 \mathrm{~mm}$ & range $10-54 \mathrm{~mm}$ & \\
\hline \multicolumn{4}{|l|}{ Complications } \\
\hline Biloma & $27(13 \%)$ & $18(16 \%)$ & 0.054 \\
\hline Bile leakage & $2(1 \%)$ & $3(2.6 \%)$ & 0.001 \\
\hline
\end{tabular}


were executed as anatomic or non-anatomic resections with the goal of maximal parenchymal preservation by non-anatomic resection. Dissection was accomplished using SonaStar by Misonix, allowing precise, nonanatomic resections. Major hepatectomy was defined as resection of three or more liver segments. Patients with synchronous colorectal and liver tumor at the time of presentation were assessed for feasibility of single stage combined colon and liver resection by the multidisciplinary team. In general, younger patients in good general condition and no significant comorbidity conditions were deemed candidates for single stage combined liver and colon resections.

\section{Haemostatic agents}

Glubran2 is a synthetic surgical glue, (CE Mark) certificated for internal and external use, with haemostatic, adhesive, sealer, and bacteriostatic properties. When used in moist environment, it quickly polymerizes into a thin elastic film which has high tensile strength and firmly adheres to the anatomy of the tissue on which it is applied. Once it is polymerized, Glubran2 acts as a bio inert material. We used 1 package of $1 \mathrm{~mL}$ Glubran2 for each patient.

\section{Lesion confirmation: reference standard}

Two pathologists, specialized in the liver, performed histopathologic analysis of resected specimens. Lesion confirmation was based on the pathologic diagnosis of surgically resected liver specimens. The resected specimens were processed and then sectioned with a $5-\mathrm{mm}$ slice thickness. All tumor samples were stained with hematoxylin and eosin coloration. Immunohistochemistry stains were obtained to confirm the intestinal origin of the metastatic lesions. The panel of immunohistochemical markers included cytokeratin 7, cytokeratin 20, and CDX2. The histopathological report included the pushing or infiltrating growth and the presence or absence of tumor budding and/or fibrosis and necrosis.

\section{Follow-up}

$\mathrm{Al}$ patients underwent to US and $\mathrm{CT}$ at 1 month post surgical resection. A MDCT study was performed at 3th, 6th and 12th month. MRI study was a problem-solving tool for patients with suspicious of recurrence disease or in which a complication was detected.

OS was defined as the interval (in months) from the date of partial hepatectomy to the date of death.

\section{MDCT protocol}

CT studies were performed with a 64-detector row scanner (Optima 660, GE Healthcare, USA), using the following scanning parameters: $120 \mathrm{kVp}, 100-470 \mathrm{mAs}$ (NI 16.36) and 2.5-mm slice thickness. Liver protocol study in our Cancer Center includes a quadruple phases contrast study with an unenhanced, an arterial, a portal/venous, and equilibrium phases. Images acquisition in the arterial phase is started after attenuation in the descending aorta reached $120 \mathrm{HUs}$, measured with the bolus tracking method. For the portal/venous phase, the images were acquired $33 \mathrm{~s}$ after the arterial phase. For the equilibrium phase, images were acquired $180 \mathrm{~s}$ after the contrast medium injection.

\section{MR Imaging Protocol}

MR studies were performed by using a $1.5 \mathrm{~T}$ scanner (Magnetom Symphony, with Total Imaging Matrix Package, Siemens, Erlangen, Germany) with an 8-element body coil and a phased array coil. Detailed information regarding the MR study protocol is summarized in Table 2. A standard dose $(0.025 \mathrm{mmol} / \mathrm{kg})$ of gadoxetic acid (Primovist, Bayer Healthcare, Berlin, Germany) was injected at a rate of $1.0 \mathrm{~mL} / \mathrm{s}$ by using a power injector (Spectris Solaris EP; Medrad, Warrendale, Pa) followed by a $30-\mathrm{mL}$ saline flush. Arterial phase images were acquired $7 \mathrm{~s}$ after contrast medium arrival at the thoracic aorta by using an MR fluoroscopic monitoring system. Thereafter, portal venous phase, transitional phase, and hepatobiliary phase (HBP) were obtained $60 \mathrm{~s}, 3 \mathrm{~min}$, and 20 min after contrast medium injection, respectively.

\section{CEUS protocol}

CEUS was always preceded by a careful US survey, assessing the size and appearance of the lesion/s. This baseline assessment was done to appropriately choose the liver area or areas to be particularly focused in the forthcoming contrast-enhanced part of the US study. In all cases, a separated injection was performed for each liver lobe. For both injections, the arterial phase assessment was focused on any known lesion at baseline US. CEUS was performed as a low- mechanical index, double-split mode, real-time modality. We employed a Technos MyLab 70 XVG and MyLab Twice scanner (Esaote, Genoa, Italy), injecting $2.4 \mathrm{ml}$ of a sulfur hexafluoride-based contrast medium (SonoVue, Bracco, Milan, Italy) per each liver lobe. After the injection, the radiologist focused the sonographic field of view on the parenchymal area of interest, waiting for the microbubble's arrival. Thereafter, he/she moved the transducer to explore the remaining parenchyma of each lobe, with special reference to the resected area.

\section{Biloma and bile leakage definition, diagnosis and management}

Following scientific Literature we considered biloma as an encapsulated collection of bile outside the biliary tree and within the abdominal cavity and bile leakage as a postoperative loss of fluid bile via abdominal drains after 
Table 2 Detailed information regarding the MR imaging parameters

\begin{tabular}{lllllll}
\hline Sequence & Orientation & $\begin{array}{l}\text { TR/TE/FA } \\
(\mathbf{m s} / \mathbf{m s} / \mathbf{d e g} \text { ) }\end{array}$ & $\begin{array}{l}\text { AT } \\
(\mathbf{m i n})\end{array}$ & Acquisition Matrix & ST/Gap (mm) & FS \\
\hline Trufisp T2-W & Coronal & $4.30 / 2.15 / 80$ & 0.46 & $512 \times 512$ & $4 / 0$ & without \\
HASTE T2-W & Axial & $1500 / 90 / 170$ & 0.36 & $320 \times 320$ & $5 / 0$ & Without and with (SPAIR) \\
HASTE T2W & Coronal & $1500 / 92 / 170$ & 0.38 & $320 \times 320$ & $5 / 0$ & without \\
In-Out phase T1-W & Axial & $160 / 2.35 / 70$ & 0.33 & $256 \times 192$ & $5 / 0$ & without \\
DWI & Axial & $7500 / 91 / 90$ & 7 & $192 \times 192$ & $3 / 0$ & without \\
Vibe & Axial & $4.80 / 1.76 / 12$ & 0.18 & $320 \times 260$ & $3 / 0$ & with (SPAIR) \\
T1-W & & & & & &
\end{tabular}

Note. TR Repetition time, TE Echo time, FA Flip angle, AT Acquisition time, ST Slice thickness, FS Fat suppression, SPAIR Spectral adiabatic inversion recovery

liver surgery $[19,20]$. We diagnosed and divided bile leakage in grade A, B and C based on the impact of this complication on patients' clinical management. [20]

\section{Surgical complications}

Surgical Complications were classified according to Clavien Dindo et al. [21].

\section{Statistical analyses}

Each continuous variable was expressed in terms of median value \pm range while each variable categorical was summarized by frequencies and percentages. Chi square test was performed to assess statistically significant difference between percentage values. Mann Whitney non parametric test were used to compare a continuous variable between 2 groups. A $p$ value $<0.05$ was considered statistically significant.

All statistical analysis was performed with SPSS for Windows (Version 23.0; SPSS Inc, Chicago, Ill).

\section{Results}

We analyzed a total of 318 patients: Group A with 205 patients and 1036 pathologically proven lesions (mean tumor size: $32 \mathrm{~mm}$; range 8-64 $\mathrm{mm}$ ) and Group B with 113 patients and $452 \mathrm{mCRC}$ pathologically proven lesions (mean tumor size: $36 \mathrm{~mm}$; range $11-59 \mathrm{~mm}$ ).

In the Group A we performed 60 lobectomy, 43 mesohepatectomy, 48 bi-segmentectomy (73\% major hepatectomy) and 54 segmentectomy or other liver resection (wedge/metasasectomy) (2 in seg I, 3 in seg II, 4 in seg III, 10 in seg IV, 9 in seg V and 8 in seg VI, 18 in seg. VII). Twenty-five patients underwent single stage combined liver and colon resections.

The average hospitalization time was 8 days $(7-16)$. No major complications occurred during surgical procedures. No patients died during hospitalization and the 30 -day mortality was $0 \%$. During follow-up in 27 patients $(13 \%)$ was reported a Biloma and in 2 patients (1\%) a bile leakage grade B was detected. No adverse events were reported regarding the use of Glubran 2.
About Group B (113 patients), 56 patients underwent major hepatectomy (49,5\%), 40 liver segmentectomy (35.5\%), 17 wedge procedure or metasasectomy (5 in seg II, 2 in seg III, 3 in seg IV, 2 in seg V and 5 in seg VI). Seventeen patients underwent single stage combined liver and colon resections.

The average hospitalization time was 10 days (5-14). No major complications occurred during surgical procedures. No patients died during hospitalization and the 30-day mortality was $0 \%$.

During follow-up 18 patients (16\%) showed presence of biloma and in 3 patients $(2,6 \%)$ a bile leakage was detected ( 2 grade $B, 1$ grade $C$ ).

A new hepatic lesions were identified (mean time 5 months) in 32 patients (15,6\%), 13 in group A and 19 in group B.

\section{Discussion}

The rationale behind our study is the polymerization of cyanoacrylate glue when it is in contact with blood and tissues owing to the presence of ions and proteins. Nowadays the solid polymer created by this reaction, has demonstrated to be safe and useful in several use during surgical clinical practices.

In surgery for ventral hernia repair, Glubran2 permitted a suturless fixation mesh, in bariatric surgery showed to be effective to prevent gastric fistulas or suture line dehiscence (leaks), in endovascular surgery many scientific articles had described it's use to stop bleeding in elective and in emergency and new applications are investigate in colorectal and thoracic surgery, to prevent anastomotic and air leak [22-28].

Our study is focused on biliostatic effect of cyanoacrylate glue but, in Literature, is possible to find articles that analyzed or compare hemostatic or sealant agent to prevent bile leakage and hemorrhagic events. López-Guerra D et al., in 2019, compare the use of two different fibrin sealant patches during liver surgery. Contrary to ours, this study included benign patients, patients without pre-operative chemotherapy, HCC and $\mathrm{mCRC}$ and concluded with no superiority between different fibrin 
patches in post-operative complications not focusing attentions on bile leakage [18].

Likewise others papers compare different agent both on prevent bleeding and bile leakage and, similarly to López-Guerra D et al., their population study included not only mCRC patients [29-31].

Also Briceño J et al., evaluating a fibrin sealant, concluded advising the use of this agent during liver surgery due to the decrease moderate and severe postoperative complications with no clarification on bile leakage impact [29].

Precisely for this, our study acquire relevance because this is the first study that assesses the safety and efficacy of Glubran2 as a biliostatic agent, at the best of our knowledge, focusing attention to prevent bile postopertive complications.

This project was inspired by the evolution of neoadjuvant chemotherapy for colorectal liver metastases. Thanks to the use of new drugs, especially anti-angiogenetic monoclonal antibody added to usual chemotherapy, has become possible to treat surgically patients with more curative intent due an increase response rates conversion to resectability and long-term survival. This is a very important result considering that hepatic resection is the only curative option for patients with colorectal liver metastases (mCRC) [1]. However, we need to consider also the neoadjuvant chemotherapy influence on surgical morbidity. The chemotherapy-related complications, steatosis, chemotherapy-associated steatohepatitis (CASH) and sinusoidal obstruction syndrome (SOS), might impair the hepatic parenchyma, thus reducing the functionality and influencing the outcome following resection $[1,2]$. Despite the results of same studies demonstrated that neoadjuvant chemotherapy did not impair outcomes of liver resections for $\mathrm{mCRC}$, in our experience we reported an increase of complications rates in this type of patients [32]. The most peculiar and important complication after liver resection is bile leakage with an incidence that is reported between 3.6 and $17 \%$ [33]. In our two groups, we evaluate and match age, sex, site of primary cancer, chemotherapy protocol, duration of chemotherapy and type of liver resection. All patients underwent to US and MDCT at one month post resection and MDCT at 3th, 6th and 12th month for the first post-operative year. In the Group A we performed major hepatectomy in $73 \%$ of patients versus $49.5 \%$ in Group B. Several researches have shown that risk of biliary complications increase with the complexity of surgical procedure [34]. Patients enrolled in Group A were compared with patients in Group B; biloma was reported in $13 \%$ (group A) vs. $16 \%$ (group B) and bile leakage in $1 \%$ (Group A) vs. $2.6 \%$ (group B) $(P$-value $<0,001$ ). All patients underwent liver resection using the same surgical open or laparoscopic approach, uniform technique and energy devices. In literature is possible to find numerous study that compared different types of advanced energetic devices and their haemostatic effect, their lateral spread damage in many tissues and no one demonstrated better result over others [35]. In all our patients, in booth groups, we used only Harmonic Scalpel in order to minimizing the intraoperative bias.

During the follow up, no patients died but a new hepatic lesions were found in 32 patients (15,6\%): 13 in Group A and 19 in Group B.

We observed no adverse events regarding the use of Glubran2. Analyzing our results, we could state that Glubran2 is a safe and efficacy biliostatic agent useful to prevent bile leakage complication after liver resection. Our results are similar to others that have shown that Glubran2 is a safe and effective hemostatic agent $[20,34,36,37]$.

The current study had several limitations: data collected derived from only one cancer centre, and a small semple size enrolled in this study may have influence the conclusion. In addition, this is a retrospective study. Therefore, further perspective multicentre analyses including more patients were needed to validate the prognostic significance of these results.

\section{Conclusions}

Answering to our primary end-point, it is possible to affirm that Glubran2 is a safe and feasible biliostatic agent useful to prevent bile leakage complication and biloma formation after liver resection.

\section{Abbreviations}

mCRC: Colorectal liver metastases; CASH: Chemotherapy-associated steatohepatitis; MDCT: Multiple detector computed tomography; CT: Computed tomography; CEUS: Contrast Enhanced Ultrasound; SOS: Sinusoidal obstruction syndrome

\section{Acknowledgements}

The authors are grateful to Alessandra Trocino, librarian and Assunta Zazzaro data manager at the National Cancer Institute of Naples, Italy.

Informed consent

Each patient signed the informed consent.

\section{Author contributions}

RP1: Data curation, Writing - original draft. VG: Conceptualization, Supervision, Data curation, Writing - review \&editing. AB: Supervision. RP2: Supervision. VA: Data curation; Formal analysis. MP: Data curation; Formal analysis. RF: Data curation; Formal analysis. FT: Data curation; Formal analysis. GN: Data curation; Formal analysis. AV: Supervision. Fl: Conceptualization, Supervision, Writing - review \& editing. The author(s) read and approved the final manuscript.

\section{Funding}

Authors have no receiving founds for this project.

Availability of data and materials

The datasets used and/or analysed during the current study are available from the corresponding author on reasonable request. 


\section{Declarations}

\section{Ethics approval and consent to participate}

This retrospective study was approved by the Ethical Committee of the National Cancer Institute "G. Pascale Foundation - IRCCS" of Naples and the requirement for patient informed consent was waived. All procedures performed in the study were in accordance with the ethical standards of the institutional and with the 1964 Helsinki declaration and its later amendments or comparable ethical standards.

\section{Consent for publication}

Each author give the consent for publication.

\section{Competing interests}

The authors declare that they have no competing interests

\section{Author details \\ 'PhD ICTH, University Federico II, Via Sergio Pansinin 5, 80131 Naples, Italy. ${ }^{2}$ Department of Support to Cancer Pathways Diagnostics Area, Radiology Unit, "Istituto Nazionale Tumori IRCCS Fondazione Pascale - IRCCS di Napoli", Naples, Italy. ${ }^{3}$ Radiology Division, "Istituto Nazionale Tumori IRCCS Fondazione Pascale - IRCCS di Napoli", Naples, Italy. ${ }^{4}$ Department Corp-S Care and Research of Cancer of the Abdominal District, Hepatobiliary Unit, "Istituto Nazionale Tumori IRCCS Fondazione G. Pascale - Napoli", Naples, Italy. ${ }^{5}$ Department of Support to Cancer Pathways Diagnostics Area, Pathology and Cytopathology Unit, "Istituto Nazionale Tumori IRCCS Fondazione G. Pascale - IRCCS Napoli", Naples, Italy. ${ }^{6}$ Department Corp-S Care and Research of Cancer of the Abdominal District, Oncology Unit, "Istituto Nazionale Tumori IRCCS Fondazione G. Pascale - IRCCS Napoli", Naples, Italy.}

Received: 29 June 2020 Accepted: 3 March 2021

Published online: 16 March 2021

\section{References}

1. Granata V, Fusco R, Avallone A, Catalano O, Piccirillo M, Palaia R, Nasti G, Petrillo A, Izzo F. A radiologist's point of view in the presurgical and intraoperative setting of colorectal liver metastases. Futur Oncol. 2018. https://doi.org/10.2217/fon-2018-0080.

2. Nordlinger B, Sorbye H, Glimelius B, et al. Perioperative chemotherapy with FOLFOX4 and surgery versus surgery alone for resectable liver metastases from colorectal cancer (EORTC Intergroup trial 40983): a randomised controlled trial. Lancet. 2008. https://doi.org/10.1016/S0140-6736(08)60455-9.

3. Granata V, Fusco R, Venanzio Setola S, Mattace Raso M, Avallone A, De Stefano A, Nasti G, Palaia R, Delrio P, Petrillo A, Izzo F. Liver radiologic findings of chemotherapy-induced toxicity in liver colorectal metastases patients. Eur Rev Med Pharmacol Sci. 2019. https://doi.org/10.26355/ eurrev_201911_19531.

4. Capussotti L, Ferrero A, Vigan'o L, Sgotto E, Muratore A, Polastri R, et al. Bile leakage and liver resection: Where is the risk? Arch Surg. 2006. https://doi. org/10.1001/archsurg.141.7.690

5. Yamashita Y, Hamatsu T, Rikimaru T, Tanaka S, Shirabe K, Shimada M, et al. Bile leakage after hepatic resection. Ann Surg. 2001. https://doi.org/10.1097/ 00000658-200101000-00008.

6. Tanaka S, Hirohashi K, Tanaka H, Shuto T, Lee SH, Kubo S, et al. Incidence and management of bile leakage after hepatic resection for malignant hepatic tumors. J Am Coll Surg. 2002. https://doi.org/10.1016/S1072-7515(02 )01288-7.

7. Bhattachariya S, Puleston J, Davidson BR, Dooley JS. Outcome of early endoscopic biliary drainage in the management of bile leaks after hepatic resection. Gastrointest Endosc. 2003. https://doi.org/10.1067/mge.2003.148

8. Lo CM, Fan ST, Liu CL, Lai EC, Wong J. Biliary Complications After Hepatic Resection. Arch Surg. 1998. https://doi.org/10.1001/archsurg.133.2.156.

9. Noun R, Elias D, Balladur P, Bismuth H, Parc R, Lasser P, et al. Fibrin glue effectiveness and tolerance after elective liver resection: A randomized trial. Hepatogastroenterology. 1996;43:221-4.

10. Hayashibe A, Sakamoto K, Shinbo M, Makimoto S, Nakamoto T. New method for prevention of bile leakage after hepatic resection. J Surg Oncol. 2006. https://doi.org/10.1002/jso.20548.
11. Boonstra EA, Molenaar IQ, Porte RJ, de Boer MT. Topical haemostatic agents in liver surgery: Do we need them?, HPB. 2009; https://doi.org/10.1111/j.14 77-2574.2009.00065.x.

12. Chen QY, Zhu XR, Zhang Y. The Hemodynamic Changes in Patients with Cerebral Arteriovenous Malformations before and after Interventional Embolization Therapy with Glubran 2 Acrylic Glue. Eur Neurol. 2017. https:// doi.org/10.1159/000478727.

13. Vakalopoulos KA, Bosmans JWAM, van Barneveld KWY, Vogels RRM, Boersema GSA, Wu Z, Gijbels MJJ, Jeekel J, Kleinrensink GJ, Bouvy ND, Lange JF. Impact of tissue adhesives on the prevention of anastomotic leakage of colonic anastomoses: an in vivo study. Int J Colorectal Dis. 2017. https://doi. org/10.1007/s00384-017-2834-4.

14. Kakaei F, Seyyed Sadeghi MS, Sanei B, Hashemzadeh S, Habibzadeh A. A randomized clinical trial comparing the effect of different haemostatic agents for haemostasis of the liver after hepatic resection. HPB Surg. 2013. https://doi.org/10.1155/2013/587608.

15. Kobayashi S, Nagano H, Marubashi S, Wada H, Eguchi H, Takeda Y, Tanemura M, Doki Y, Mori M. Fibrin sealant with PGA felt for prevention of bile leakage after liver resection. Hepatogastroenterology. 2012;59(120): 2564-8. doi: https://doi.org/10.5754/hge10315. PMID: 23178623.

16. de Boer MT, Boonstra EA, Lisman T, Porte RJ. Role of fibrin sealants in liver surgery. Dig Surg. 2012;29(1):54-61. doi: 10.1159/000335735. Epub 2012 Mar 15. PMID: 22441621

17. Kobayashi S, Takeda Y, Nakahira S, Tsujie M, Shimizu J, Miyamoto A, Eguchi H, Nagano H, Doki Y, Mori M. Fibrin Sealant with Polyglycolic Acid Felt vs Fibrinogen-Based Collagen Fleece at the Liver Cut Surface for Prevention of Postoperative Bile Leakage and Hemorrhage: A Prospective, Randomized, Controlled Study. J Am Coll Surg. 2016;222(1):59-64 Epub 2015 Oct 23. PMID: 26597705

18. López-Guerra D, Santos-Naharro J, Rojas-Holguín A, Jaen-Torrejimeno I, Prada-Villaverde A, Blanco-Fernández G. Postoperative bleeding and biliary leak after liver resection: A cohort study between two different fibrin sealant patches. Scientific reports. 2019;9(1):12001. https://doi.org/10.1038/s41598-01 9-48529-y.

19. Yousaf MN, D'Souza RG, Chaudhary F, Ehsan H, Sittambalam C. Biloma. A Rare Manifestation of Spontaneous Bile Leak. Cureus. 2020;12(5):e8116. doi: https://doi.org/10.7759/cureus.8116. PMID: 32542169; PMCID: PMC7292700.

20. Koch M, Garden OJ, Padbury R, Rahbari NN, Adam R, Capussotti L, Fan ST, Yokoyama Y, Crawford M, Makuuchi M, Christophi C, Banting S, BrookeSmith M, Usatoff V, Nagino M, Maddern G, Hugh TJ, Vauthey JN, Greig P, Rees M, Nimura Y, Figueras J, DeMatteo RP, Büchler MW, Weitz J, by the International Study Group of Liver Surgery. Bile leakage after hepatobiliary and pancreatic surgery: a definition and grading of severity. Surgery. 2011; 149(5):680-8 Epub 2011 Feb 12. PMID: 21316725.

21. Dindo D, Demartines N, Clavien PA. Classification of surgical complications: A new proposal with evaluation in a cohort of 6336 patients and results of a survey. Ann Surg. 2004. https://doi.org/10.1097/01.sla.0000133083.54934.ae.

22. Villalobos RN, Mias MC, Gas C, Maestre Y, Nogués M, Vilardell F, et al. Atraumatic laparoscopic intraperitoneal mesh fixation using a new laparoscopic device: an animal experimental study. Hernia. 2019;23(6):112332. https://doi.org/10.1007/s10029-019-02008-5.

23. Harsløf S, Krum-Møller P, Sommer T, Zinther N, Wara P, Friis-Andersen $H$. Effect of fixation devices on postoperative pain after laparoscopic ventral hernia repair: a randomized clinical trial of permanent tacks, absorbable tacks, and synthetic glue. Langenbeck's Arch Surg. 2018.

24. Pilone V, Tramontano S, Renzulli M, Romano M, Monda A, Albanese A, et al. Omentopexy with Glubran 2 for reducing complications after laparoscopic sleeve gastrectomy: Results of a randomized controlled study. BMC Surg. 2019;19(Suppl 1):1-6. Available from: https://doi.org/10.1186/s12893-0190507-7.

25. Jawhari R, Chevallier O, Falvo N, d'Athis P, Gehin S, Charles PE, et al. Outcomes of Transcatheter Arterial Embolization with a Modified N-Butyl Cyanoacrylate Glue for Spontaneous lliopsoas and Rectus Sheath Hematomas in Anticoagulated Patients. J Vasc Interv Radiol. 2018;29(2):2107. Available from: https://doi.org/10.1016/j.jvir.2017.08.006.

26. Abdulmalak G, Chevallier O, Falvo N, Di Marco L, Bertaut A, Moulin B, et al. Safety and efficacy of transcatheter embolization with Glubran ${ }^{*} 2$ cyanoacrylate glue for acute arterial bleeding: a single-center experience with 104 patients. Abdom Radiol. 2018;43(3):723-33.

27. Allama AM, Abd Elaziz ME. Using tissue glues for decreasing alveolar air leak in thoracic surgery. Asian Cardiovasc Thorac Ann. 2019;27(5):369-73. 
28. Vakalopoulos KA, Wu Z, Kroese LF, Jeekel J, Kleinrensink G, jan, Dodou D, et al. Sutureless closure of colonic defects with tissue adhesives: an in vivo study in the rat. Am J Surg. 2017;213(1):151-8. Available from: https://doi. org/10.1016/j.amjsurg.2016.05.009.

29. Briceño J, Naranjo A, Ciria R, Díaz-Nieto R, Sánchez-Hidalgo JM, Luque A, Rufián S, López-Cillero P. A prospective study of the efficacy of clinical application of a new carrier-bound fibrin sealant after liver resection. Arch Surg. 2010;145(5):482-8. doi: https://doi.org/10.1001/archsurg.2010.62. PMID: 20479348.

30. Frilling A, Stavrou GA, Mischinger HJ, de Hemptinne B, Rokkjaer M, Klempnauer J, Thörne A, Gloor B, Beckebaum S, Ghaffar MF, Broelsch CE. Effectiveness of a new carrier-bound fibrin sealant versus argon beamer as haemostatic agent during liver resection: a randomised prospective trial. Langenbecks Arch Surg. 2005;390(2):114-20. doi:https://doi.org/10.1007/ s00423-005-0543-x. Epub 2005 Feb 19. PMID: 15723234

31. Zacharias T, Ferreira N. Carrier-bound fibrin sealant compared to oxidized cellulose application after liver resection. HPB (Oxford). 2012;14(12):839-47. doi: https://doi.org/10.1111/j.1477-2574.2012.00560.x. Epub 2012 Sep 21. PMID: 23134186; PMCID: PMC3521913.

32. Bergeat $D$, Rayar M, Mouchel $Y$, Merdrignac A, Meunier B, Lièvre A, Boudjema K, Sulpice L. Preoperative bevacizumab and surgery for colorectal liver metastases: a propensity score analysis, Langenbeck's Arch. Surg. 2017. https://doi.org/10.1007/s00423-017-1551-3.

33. Kazuhiko Sakamoto T, Tamesa T, Yukio Y, Tokuhisa Y, Maeda M, Oka. Risk Factors and Managements of Bile Leakage after Hepatectomy. World I Surg. 2016. https://doi.org/10.1007/s00268-015-3156-8

34. Rossitti S. Spontaneous intracerebral and intraventricular hemorrhage: Hemostasis by transarterial glue embolization, Clin. Neuroradiol. 2010. https://doi.org/10.1007/s00062-010-0006-9.

35. Patrone R, Gambardella C, Romano RM, Gugliemo C, Offi C, Andretta C, Vitiello A, Tartaglia E, Flagiello L, Conzo A, Mauriello C, Conzo G. The impact of the ultrasonic, bipolar and integrated energy devices in the adrenal gland surgery: Literature review and our experience, BMC Surg. 18 2019; https://doi.org/10.1186/s12893-018-0457-5.

36. Loffroy R. Using Glubran 2 acrylic glue to maximize results of transcatheter arterial embolization for refractory upper gastrointestinal bleeding. Scand J Gastroenterol. 2015. https://doi.org/10.3109/00365521.2015.1040996.

37. Del Corso A, Bargellini I, Cicorelli A, Perrone O, Leo M, Lunardi A, Alberti A, Tomei F, Cioni R, Ferrari M, Bartolozzi C. Efficacy and safety of a novel vascular closure device (Glubran 2 Seal) after diagnostic and interventional angiography in patients with peripheral arterial occlusive disease. Cardiovasc Intervent Radiol. 2013. https://doi.org/10.1007/s00270-012-0428-7.

\section{Publisher's Note}

Springer Nature remains neutral with regard to jurisdictional claims in published maps and institutional affiliations.

Ready to submit your research? Choose BMC and benefit from:

- fast, convenient online submission

- thorough peer review by experienced researchers in your field

- rapid publication on acceptance

- support for research data, including large and complex data types

- gold Open Access which fosters wider collaboration and increased citations

- maximum visibility for your research: over $100 \mathrm{M}$ website views per year

At $\mathrm{BMC}$, research is always in progress.

Learn more biomedcentral.com/submissions 